\title{
First year clinical tutorials: students' learning experience
}

This article was published in the following Dove Press journal:

Advances in Medical Education and Practice

28 November 2014

Number of times this article has been viewed

\section{Annette Burgess' \\ Kim Oates ${ }^{2}$ \\ Kerry Goulston ${ }^{2}$ \\ Craig Mellis'}

'Central Clinical School, Sydney Medical School, The University of Sydney, Sydney, NSW, Australia; 2Sydney Medical School,

The University of Sydney, Sydney, NSW, Australia
Correspondence: Annette Burgess Sydney Medical School - Central, The University of Sydney, Building 63, Level 4, Royal Prince Alfred Hospital, Missenden Road, Camperdown, NSW 2050, Australia

Tel +61295158172

Email annette.burgess@sydney.edu.au
Background: Bedside teaching lies at the heart of medical education. The learning environment afforded to students during clinical tutorials contributes substantially to their knowledge, thinking, and learning. Situated cognition theory posits that the depth and breadth of the students' learning experience is dependent upon the attitude of the clinical teacher, the structure of the tutorial, and the understanding of tutorial and learning objectives. This theory provides a useful framework to conceptualize how students' experience within their clinical tutorials impacts their knowledge, thinking, and learning.

Methods: The study was conducted with one cohort $(n=301)$ of students who had completed year 1 of the medical program at Sydney Medical School in 2013. All students were asked to complete a three-part questionnaire regarding their perceptions of their clinical tutor's attributes, the consistency of the tutor, and the best features of the tutorials and need for improvement. Both quantitative and qualitative data were collected and analyzed using descriptive statistics.

Results: The response rate to the questionnaire was $88 \%$ (265/301). Students perceived that their tutors displayed good communication skills and enthusiasm, encouraged their learning, and were empathetic toward patients. Fifty-two percent of students reported having the same communications tutor for the entire year, and $28 \%$ reported having the same physical examination tutor for the entire year. Students would like increased patient contact, greater structure within their tutorials, and greater alignment of teaching with the curriculum.

Conclusion: Situated cognition theory provides a valuable lens to view students' experience of learning within the clinical environment. Our findings demonstrate students' appreciation of clinical tutors as role models, the need for consistency in feedback, the importance of structure within tutorials, and the need for tutors to have an understanding of the curriculum and learning objectives for each teaching session.

Keywords: bedside teaching, clinical tutorials, role modeling, situated cognition

\section{Introduction}

Medical students acquire attitudes, knowledge, and skills requisite for medical practice via a number of teaching and learning methods and activities. Bedside teaching, that is, teaching focused on patients and their problems, lies at the heart of medical education. Clinical tutorials provide opportunities for bedside teaching and for clinical tutors to instill the values of the medical profession, steward knowledge, and impart clinical skills. $^{2}$ The learning environment that is afforded to students during these tutorials contributes significantly to their knowledge, thinking, and learning.

In recent years, there has been a reported decline in the estimated time spent on bedside teaching in medical schools, with obstacles cited such as a high patient turnover, increased reliance on technology, competing interests of tutors, and inadequate 
tutor training. ${ }^{3}$ However, bedside teaching provides a unique learning situation where clinical examination skills, as well as a caring attitude, can be taught by example and practiced. Bedside teaching can promote a deeper engagement of the students with learning from faculty, patients, and each other. Here, there are three sources of interaction between the patient, the tutor, and the student that can promote student engagement with learning.

Situated cognition theory promotes active, participatory learning, where knowing, thinking, and learning are dependent upon the environment, and bound to the social and physical context. ${ }^{4}$ This theory provides a useful framework to conceptualize how students' experience within their clinical tutorials impacts knowledge, thinking, and learning. Thus, situated cognition theory represents a significant shift in cognitive science theory, providing a move away from information processing theory, where socially constructed knowledge is not apparent. ${ }^{5}$

Clinical tutorials afford students with opportunities to practice their clinical skills under guidance and supervision of a clinical tutor. In accordance with situated cognition theory, the depth and breadth to which students are able to embrace this learning experience is dependent upon several key factors, including attitude of the clinical tutor, structure of the tutorial, and understanding of tutorial and learning objectives.

The aim of this study was to explore medical students' experience of their first year of clinical tutorials. Viewing learning within tutorials through the lens of situated cognition theory provides a framework to understand student insights and perspectives.

\section{Context}

Sydney Medical School offers a 4-year graduate entry medical program. First year medical students attend the university main campus 4 days per week, and their "parent" clinical school one day per week. Parent clinical schools are based at one of six metropolitan teaching hospitals. These schools provide invaluable clinical experience in a variety of settings. There, from the first week of the program, on a weekly basis, students take part in small group, bedside clinical tutorials. Students attend 1.5 hours of physical examination teaching, and 1.5 hours of communications teaching. Groups consist of six to seven students, with one clinician who is either a senior specialist (consultant), registrar (house staff), or general practitioner.

\section{Materials and methods}

The study was conducted with one cohort ( $n=301)$ of students who had completed year 1 of the medical program in 2013.
At the commencement of year 2 in 2014, all students were asked to complete a three-part questionnaire regarding their experience of clinical tutors and clinical tutorials in year 1 .

\section{Student perception of clinical tutor attributes}

The questionnaire contained nine closed questions using a Likert scale of 1-5, with responses ranging from "strongly disagree" (1) to "strongly agree" (5). The questions were developed based on the positive characteristics of role models reported in literature. ${ }^{6-8}$ The questions related specifically to students' experience of their clinical tutor as a role model. Descriptive statistics were used to analyze these data. ${ }^{9}$

\section{Consistency of tutors}

Students were also asked three questions regarding the consistency of tutors, to elicit yes or no responses.

\section{Best features of the tutorial and suggested improvements}

The questionnaire also contained two open-ended questions regarding the best features of their stage 1 clinical teaching experience and suggestions for improving their stage 1 clinical teaching experience. A thematic analysis of the qualitative data was carried out using framework analysis. The initial analysis was inductive and grounded in the data, and conducted by the first author on a sample of the data. Recurrent themes and subthemes were identified to inform the development of a coding framework. Once the data had been coded and categorized into themes, the data within each theme were quantified in order to measure thematic prevalence. Ethics approval was obtained from The University of Sydney ethics committee.

\section{Results}

The response rate to the questionnaire was $88 \%(266 / 301)$.

\section{Student perception of clinical tutor attributes}

Results for each of the nine closed questions are reported in Figure 1. Students perceived that their tutors displayed good communication skills and enthusiasm, encouraged learning, and were empathetic toward patients. Although students reported that their tutors provided them with a reasonable amount of individual patient contact, it seems that often 


\section{Students' perceptions of first year clinical tutor attributes $(\mathrm{n}=\mathbf{2 6 5})$}

0\% 10\% 20\% 30\% 40\% 50\% 60\% 70\% 80\% 90\% 100\%

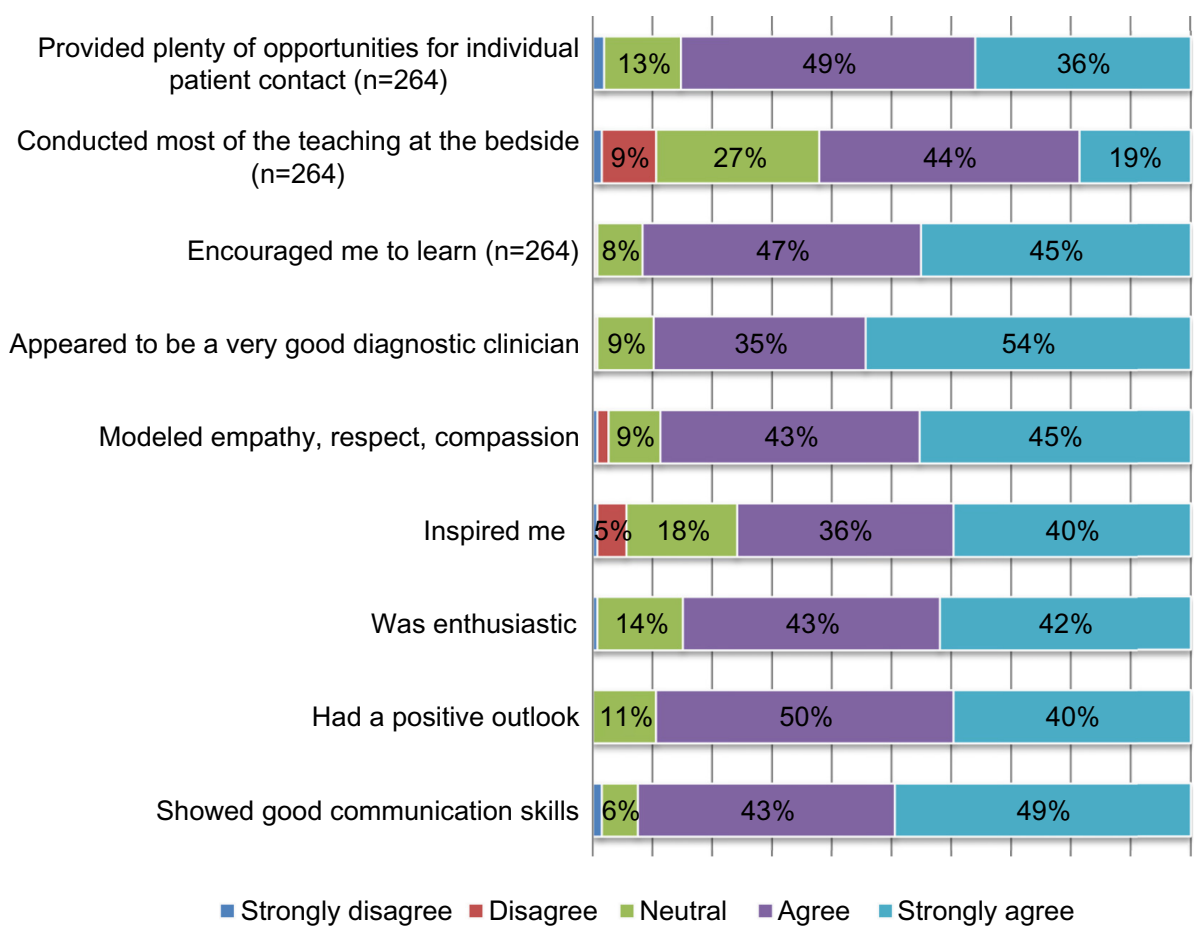

Figure I Students' perceptions of first year clinical tutor attributes.

teaching was not conducted at the bedside, which is the intention of clinical tutorials.

\section{Consistency of tutors}

The consistency of tutors is reported in Figure 2. Fifty-two percent of students reported that they had the same communications tutor for the entire year, and $28 \%$ of students reported having the same physical examination tutor for the entire year. When asked whether students thought it was important to have the same tutor for the entire year, $48 \%$ said "yes" and 52\% said "no".

\section{Best features of tutorials and suggested improvements}

Tables 1 and 2 summarize, respectively, student responses to the questions regarding the best features of the clinical tutorials, and areas needing improvement.

\section{Consistency of first year clinical tutors at Sydney Medical School $(n=265)$}

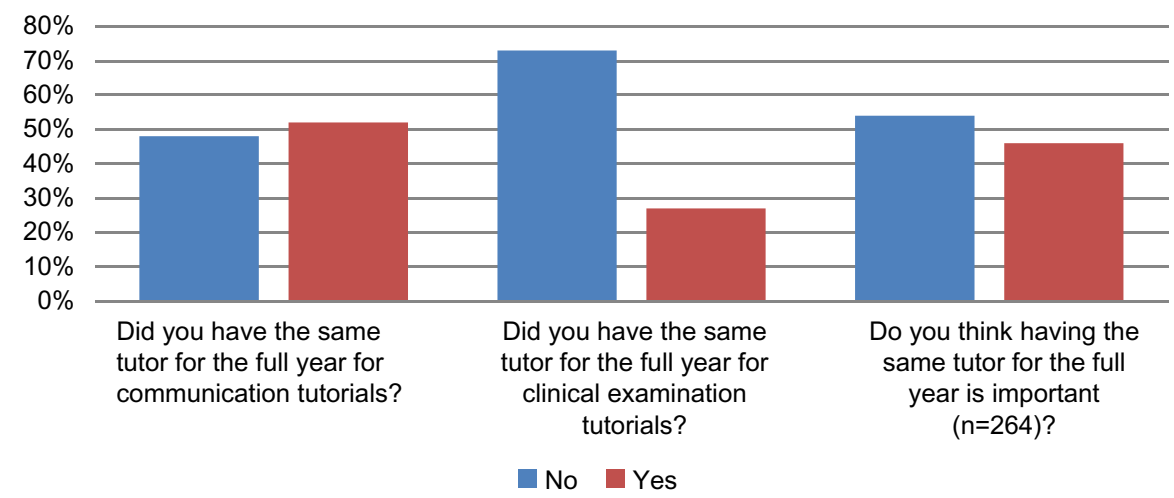

Figure 2 Students' responses to questions regarding consistency of tutors. 
Table I Best features of the clinical tutorials $(n=265)$

\begin{tabular}{ll}
\hline Student comment & $\begin{array}{l}\text { Number of similar } \\
\text { comments (\%) }\end{array}$ \\
\hline $\begin{array}{ll}\text { "Time spent on the wards, with opportunities } \\
\text { to practice history and examination skills with }\end{array}$ & $62(23 \%)$ \\
$\begin{array}{l}\text { patients" } \\
\text { "Enthusiastic teachers" }\end{array}$ & $12(5 \%)$ \\
"Encouraging tutors" & $10(4 \%)$ \\
\hline
\end{tabular}

\section{Discussion}

Theories that inform educational practice offer valuable lenses through which to analyze learning. Utilizing situated cognition theory as a conceptual framework, we illustrate the students' perceived experience of their clinical tutorials in the first year of the medical program. In accordance with situated cognition theory, ${ }^{4}$ students' learning experience is dependent upon three key factors: the attitude of the clinical tutor; the structure of the tutorial; and tutor and student understanding of the tutorial and learning objectives.

\section{Attitude of the clinical tutor}

\section{Teacher as a role model}

The tutor is one of the most powerful variables in the educational setting. Students learn via observation, imitation, and modeling of their tutors. ${ }^{10}$ Although subject expertise is important, alone it is not sufficient to make a good teacher. ${ }^{1}$ The teacher's actions, attitudes, and enthusiasm for the subject will affect learners indirectly. ${ }^{11}$ Students' responses to closed questions indicate that tutors' demonstrations of these elements were highly valued by students. Overwhelmingly, students found their tutors modeled empathy, respect, and compassion during patient interactions. Open-ended comments from students also revealed that "enthusiastic" and "encouraging" tutors improved their learning environment. Role models, such as clinical tutors who are experts in the cognitive and psychosocial aspects of the medical profession, play an important part in exemplifying professional identity in medicine. ${ }^{12}$

\section{Affordance of patient contact}

Learning that takes place in the hospital setting fosters enduring elements of practice that cannot be easily learned from books. Distinct from knowledge, practical elements, such as ways to interact with patients, are passed on and understood within meaningful learning environments. ${ }^{13,14}$ The authentic hospital setting offers opportunities for learning as a social activity. During clinical tutorials, observed and participatory social interactions, such as those with patients, are central to learning. Almost a quarter (23\%) of students commented that the best feature of the tutorial was the opportunities afforded by their clinical tutor to spend time on the wards and interact with patients. In fact, $17 \%$ of students commented that they would like more patient contact, with greater opportunities for each individual student to practice history and examination skills in preparation for their own clinical examinations.

It is concerning that only $63 \%$ of students reported that most of the teaching during clinical tutorials was conducted at the bedside. While students highly value the bedside as an excellent place to learn clinical skills, teachers often avoid this as a place of teaching, and sometimes lack experience and adequate training. ${ }^{15}$ Often tutors may be uncomfortable teaching in the presence of a patient, even though research has shown that patients enjoy and often benefit from bedside teaching. ${ }^{15,16}$

\section{Provision of meaningful feedback}

There is extensive literature explaining how important feedback is to the recipient. It is one of the few ways students can determine how they are progressing and how they can improve. ${ }^{17}$ Self-evaluation is notoriously wrong. ${ }^{18}$ Commonly, students complain that they are not given adequate feedback

Table 2 Suggested improvements for clinical tutorials

\begin{tabular}{|c|c|}
\hline Student comment & $\begin{array}{l}\text { Number of similar } \\
\text { comments (\%) }\end{array}$ \\
\hline $\begin{array}{l}\text { "More supervised patient contact time, with opportunities for individual examination and history-taking practice. Some tutors } \\
\text { rarely took us to see patients. The patients should have relevant conditions." }\end{array}$ & 45 (I7\%) \\
\hline $\begin{array}{l}\text { "More structured history and examination tutorials that follow the curriculum. Many of our tutors did not follow the } \\
\text { handbook. More systematic teaching better integrated with the curriculum, standardized across clinical schools." }\end{array}$ & $36(14 \%)$ \\
\hline $\begin{array}{l}\text { "Tutors should be briefed as to what is expected of them. They should know the curriculum and they should prepare } \\
\text { for the tutorial. They should teach at the appropriate level for first year students." }\end{array}$ & $29(11 \%)$ \\
\hline $\begin{array}{l}\text { "More introduction to the tutorial and practice on examination and physiology beforehand, so we can be more confident } \\
\text { when doing it on the ward." }\end{array}$ & 22 (8\%) \\
\hline $\begin{array}{l}\text { "More frequent feedback that is constructive. Tutors should expect more from us, and push us to learn. They should not be } \\
\text { reserved in criticism, they should expect more and give us homework." }\end{array}$ & $18(7 \%)$ \\
\hline “Longer tutorials, more teaching hours, more clinical time.” & $16(6 \%)$ \\
\hline
\end{tabular}


about their performance and progress. It has previously been reported in medical education that the only feedback received is vague and ineffective. ${ }^{19} \mathrm{~A}$ number of students (7\%) commented that they would like more frequent and more constructive feedback from tutors. Given that no more than $52 \%$ of students had the same communications tutor for the entire year, greater consistency in observation and feedback may be beneficial to our students. This is in line with literature stating that in order for feedback to be accurate and constructive, direct observation of students is needed in a number of patient interactions. ${ }^{19}$

\section{Structure of tutorials}

\section{Preparation prior to ward activities}

In order for students to learn, they must be offered opportunities for meaningful participation in tutorials. ${ }^{20}$ However, it is important to determine the optimum balance between supervision and autonomy within clinical tasks. ${ }^{21} \mathrm{~A}$ formal introduction and preparation at the commencement of each tutorial was requested by $8 \%$ of students as a way to maximize their learning experience on the wards.

\section{Alignment of tutorials with curriculum}

Learning is an active process, and the tutor's role is to act as a facilitator. ${ }^{1}$ A significant proportion (14\%) of students requested more structure to their tutorials, with more systematic teaching that is integrated and aligned with the curriculum and standardized across all clinical schools. Although difficult to achieve due to variability of the clinical setting, an appropriate patient is needed in alignment with the outlined teaching for the week. ${ }^{22}$

\section{Length of tutorials}

A small but significant number of students (6\%) commented that they would like longer tutorials with "more clinical time". Situated cognition argues that learning involves processing information through interplay between existing and new knowledge. If new knowledge is to be actively acquired, sufficient time must be provided for new experiences. ${ }^{23}$

\section{Understanding of tutorials and learning objectives}

A common problem with clinical teaching is the lack of clear objectives and expectations, and a lack of congruence or continuity with the curriculum. ${ }^{1}$ Both the tutor and the student benefit from a clear understanding of the learning objectives. Our results emphasize the importance of tutors being prepared and familiar with the curriculum, with $11 \%$ of students commenting that tutors should be more aware of what is required in teaching, and that teaching should be pitched at the right level. Where possible, activities should be aligned with the individual learner's needs, with the level of challenges being progressively increased. ${ }^{24}$

There is clear evidence that tutors need to spend time planning before commencing a teaching session. ${ }^{25}$ Learning objectives should be decided upon before the session, be achievable in the time available, and relevant to the students' needs. Importantly, they should be pitched at the appropriate level for the students, with literature suggesting tutorials are usually pitched too high. ${ }^{1,22}$ Students need to be informed at the commencement of the session what the learning objectives are, what teaching methods will be used, and what is expected of them as a result of the teaching session. ${ }^{1}$

\section{Conclusion}

Situated cognition theory provides a valuable lens to view students' experience of learning within the clinical environment. Knowledge, thinking, and learning are grounded in experience, and bound to the social and physical context. Three key environmental elements that learning is dependent upon include the attitude of the clinical tutor, the structure of the tutorial, and the tutor and students' understanding of the learning objectives. Our findings demonstrate students' appreciation of clinical tutors as role models; the need for consistency of feedback; the importance of structure within tutorials; the need for tutors to have an understanding of the curriculum, and to clearly define the learning objectives for each teaching session; and the need for tutors to take time to brief students at the commencement of each tutorial.

\section{Disclosure}

The authors report no conflicts of interest in this work.

\section{References}

1. Spencer J. Learning and teaching in the clinical environment. $B M J$. 2003;326:591.

2. Cox A. What are communities of practice? A comparative review of four seminal works. Journal of Information Science. 2005;31:527-540.

3. Shehab A. Clinical teachers' opinions about bedside-based clinical teaching. Sultan Qaboos Univ Med J. 2013;13:121-126.

4. Durning S, Artino A. Situativity theory: a perspective on how participants and the environment can interact: AMEE Guide no 52. Med Teach. 2011;33:188-199

5. Kirshner D, Whitson JA, editors. Situated Cognition: Social, Semiotic, and Psychological Perspectives. Mahwah, NJ, USA: Lawrence Erlbaum; 1997.

6. Asghari F, Fard NN, Atabaki A. Are we proper role models for students? Interns' perception of faculty and residents' professional behavior. Postgrad Med J. 2011;87:519-523. 
7. Wright S. Examining what residents look for in their role models. Acad Med. 1996;71:290-292.

8. Passi V, Johnson S, Peile E, Wright S, Hafferty F, Johnson N. Doctor role modelling in medical education. The BEME Collaboration. Med Teach. 2013;35:e1422-e1436.

9. Creswell J. Educational Research: Planning, Conducting and Evaluating Quantitative and Qualitative Research. Upper Saddle River, NJ, USA: Merrill; 2002.

10. Hesketh EA, Bagnall G, Buckley EG, et al. A framework for developing excellence as a clinical educator. Med Educ. 2001;35: $555-564$.

11. Harden RM, Crosby J. AMEE Guide No 20. The good teacher is more than a lecturer - the twelve roles of the teacher. Med Teach. 2000;22: 334-347.

12. Brown JS, Collins A, Duguid P. Situated cognition and the culture of learning. Educ Res. 1999;18:2-42.

13. Flyvbjerg B. Making Social Science Matter. Cambridge, UK: Cambridge University Press; 2002.

14. Hilton SR, Slotnick HB. Proto-professionalism: how professionalisation occurs across the continuum of medical education. Med Educ. 2005;39: $58-65$.

15. Nair B, Coughlan J, Hensley M. Impediments to bed-side teaching. Med Educ. 1998;32:159-162.

16. Simons RJ, Bailey RG, Zwillich CW. The physiological and psychological effects of the bedside presentation. N Engl J Med. 1989;321: $1273-1275$
17. Cantillon P, Sargeant J. Giving feedback in clinical settings. BMJ. 2008;337:a1961.

18. Van den Berg I, Admiraal W, Pilot A. Peer assessment in university teaching: evaluating seven course designs. Assessment and Evaluation in Higher Education. 2006;31:19-36.

19. Vickery AW, Lake FR. Teaching on the run tips. 10: Giving feedback. Med J Aust. 2005;183:267-268.

20. Morris C. Replacing 'the firm': re-imagining clinical placements as time spent in communities of practice. In: Cook V, Daly C, Newman M, editors. Work Based Learning in Clinical Settings - Insights from Socio-Cultural Perspectives. Oxford, UK: Radcliffe Medical; 2012.

21. Kennedy TJ, Regher G, Baker GR, Lingard LA. Progressive independence in clinical training: a tradition worth defending? Acad Med. 2005;80:S106-S111.

22. Mellis CM. Optimizing training: what clinicians have to offer and how to deliver it. Paediatr Respir Rev. 2008;9:105-113.

23. Kaufman DM, Mann KV, Jennett P. Teaching and Learning in Medical Education: How Theory can Inform Practice. London, UK: Association for the Study of Medical Education; 2000.

24. Biggs J. Enhancing teaching through constructive alignment. Higher Education. 1996;32:347-364.

25. Lake FR, Ryan G. Teaching on the run tips 3: planning a teaching episode. Med J Aust. 2004;180:643-644.
Advances in Medical Education and Practice

\section{Publish your work in this journal}

Advances in Medical Education and Practice is an international, peerreviewed, open access journal that aims to present and publish research on Medical Education covering medical, dental, nursing and allied health care professional education. The journal covers undergraduate education, postgraduate training and continuing medical education

\section{Dovepress}

including emerging trends and innovative models linking education, research, and health care services. The manuscript management system is completely online and includes a very quick and fair peer-review system. Visit http://www.dovepress.com/testimonials.php to read real quotes from published authors. 